\title{
Outcome of Polypropylene Suture Versus Tissue Adhesive Sealing for Mesh Fixation in Hernioplasty: A Comparative Study
}

\author{
Mallikarjun $\mathrm{N} \mathrm{H}^{1}$, R. Chandrasekaran ${ }^{2}$, Himanshu Raj ${ }^{3}$ \\ ${ }^{1}$ Resident, ${ }^{2}$ Professor, ${ }^{3}$ Assistant Professor, Department of Surgery, Aarupadai Veedu Medical College and Hospital, \\ Kirumampakkam, Pondicherry, India
}

Corresponding author: Dr.Mallikarjun N H, Resident Department of Surgery, Aarupadai Veedu Medical College and Hospital, Kirumampakkam, Pondicherry, India.

DOI: http://dx.doi.org/10.21276/ijcmsr.2019.4.3.5

How to cite this article: Mallikarjun N H, R. Chandrasekaran, Himanshu Raj. Outcome of polypropylene suture versus tissue adhesive sealing for mesh fixation in hernioplasty: a comparative study. International Journal of Contemporary Medicine Surgery and Radiology. 2019;4(3):C23-C27.

\section{A B S T R A C T}

Introduction: Inguinal hernia is one of the most common cause of consultations in surgery OPD particularly in male patients above 50 years of age. Hernia repair using a mesh is being frequently used in these patients. One of the most important concern in patients undergoing hernia repair is chronic post-operative pain which may be severe enough to affect the quality of life of the patients. Traditionally sutures were used to fix the mesh in this surgery but recently synthetic glue is also being frequently used for the purpose of fixing mesh. We conducted this study to compare time required for surgery, postoperative pain, complications and recurrence rates in patients in whom either polypropylene sutures or tissue adhesive sealing was used for fixing mesh during hernia repair.

Material and Methods: This was a prospective study conducted in the department of surgery in a tertiary care medical college situated in an urban area. Institutional ethical committee approved the study and informed consent was obtained from the patients. Total 60 patients were included in this study on the basis of a predefined inclusion and exclusion criteria. Out of the 60 studied cases in 30 patients mesh fixation was done using polypropylene suture material (Group A) and in remaining 30 patients synthetic tissue adhesive glue was used for mesh fixation (Group B). Time required for surgery, postoperative pain, complications and recurrence rates in patients in whom either sutures or tissue adhesive glue was used for fixing mesh during hernia repair were compared. The statistical analysis was done using SSPS 21.0. P value less than 0.05 was taken as statistically significant.

Results: In this study Out of 60 cases there were 48 (80\%) males and 12 (20\%) females with a M:F ratio of 1:0.25. The mean age of patients in group $A$ and group $B$ was found to be comparable with no statistically significant difference $(P>0.05)$. The mean duration of surgery in group $A$ and group $B$ was found to be 52.32 +/- 14.74 minutes and $43.92+/-10.64$ minutes respectively $(P<0.05)$. Postoperative mean VAS scores were found to be comparable in both the groups with no statistically significant difference $(P>0.05)$. Chronic postoperative pain was more common in suture group as compared to patients in glue group. Recurrence rates were found to be comparable ( $P>0.05)$.

Conclusion: Fixation of mesh by synthetic tissue adhesive glue in inguinal repair is a superior choice as compared to fixation by polypropylene sutures as it is associated with reduced duration of surgery, better results in terms of chronic postoperative pain and comparable recurrence rates.

Keywords: Inguinal hernia, Mesh, Synthetic Glue, Polypropylene Sutures, Post-operative Pain.

\section{INTRODUCTION}

Abdominal hernia is common, with the prevalence on $1.7 \%$ for all ages and $4 \%$ for those aged over 45 years. Inguinal hernia's account for $75 \%$ of abdominal wall hernia, with a life time risk of $27 \%$ in men and $3 \%$ in women ${ }^{1}$ Lichtenstein hernioplasty first described in 1989, is a widely accepted technique for open repair for inguinal hernia due to its safety, efficacy and recurrence rate. ${ }^{2}$ Prosthetic mesh is routinely used to repair abdominal wall hernias. Use of mesh for hernia repair is associated with excellent results with very low recurrence rates. Several techniques are used for mesh implantation, but most involve suture to anchor mesh in position thereby preventing migration, wrinkling and curling. Suture placement is time consuming and often challenging. ${ }^{3}$ Sutures cause extensive tissue tension, predisposition to infection, and nerve entrapment, causing prolonged postoperative pain. ${ }^{4}$ In order to avoid the above disadvantages, it was proposed that polypropylene mesh be applied with less or without suture fixation to the surrounding tissue. ${ }^{5}$ Use of cyanoacrylate glue for mesh fixation in laparoscopic hernia repair was first described in $1998 .^{6}$ The use of cyanoacrylate 
glue in open Lichtenstein repair was reported in 1993 followed by mesh fixation in laparoscopic hernia repair using NBCA glue. ${ }^{7}$ The choice of mesh type and variants of hernioplasty to close an abdominal wall defect are still the subjects of discussion. ${ }^{8}$ Many researchers have found that use of glue for mesh fixation is associated with decrease operation time as well as it reduces physical work of suturing by the operating surgeon. Moreover, unlike non-absorbable sutures which requires postoperative removal glue doesn't need any post-operative care or procedure.

Use of sutures may be associated with complications such as hematoma formation, granulomatous reaction, wound dehiscence amongst the others. These complications are very rare when wound is closed with synthetic glue which is known to solidify immediately upon contact with water and blood. Use of tissue adhesive as an alternative to permanent fixation devices has been a topic of interest amongst researchers and surgeons alike. The decreased incidence of abdominal pain, reduced time for surgery and reduced work load on surgeons had been the main advantages of using tissue adhesive sealing in mesh fixation in hernioplasty as compared to using polypropylene sutures. The adhesive which are used for sealing in mesh fixation can be divided into 3 main categories and mainly consist of biologic products such as fibrin, synthetic glue such as cyanoacrylate adhesive and genetically engineered glues. Amongst these uses of synthetic glue is widespread in many surgical branches. ${ }^{9}$

Synthetic glue such as cyanoacrylate is being increasingly used for therapeutic interventions in urology (ureteral occlusion for urinary leakage with ureteral stump following cystectomy), ophthalmology (to close macular holes, conjunctival closure following vitrectomy and as antibiotic membrane patches ), otorhinolaryngology (for tissue adhesion, support of wound healing ) and in surgery (mesh fixation for hernia repair). With this background we conducted this prospective study to compare the outcome of synthetic adhesive sealing for mesh fixation with polypropylene suture material in mesh fixation in hernioplasty.

\section{MATERIAL AND METHODS}

This was a prospective study conducted in the department of surgery in a tertiary care medical college situated in an urban area. The duration of the study was 18 months. Institutional ethical committee approved the study and an informed written consent was obtained from all the patients who had been enrolled in this study. Adult patients admitted in department of surgery with the diagnosis of inguinal hernia were enrolled in this study on the basis of a predefined inclusion and exclusion criteria. A total of 60 patients were enrolled in this study. Out of the 60 studied cases in 30 patients mesh fixation was done using polypropylene suture material (Group A) and in remaining 30 patients synthetic adhesive glue was used for mesh fixation (Group B).

Demographic details such as age, gender and residence of all the patients was noted. Presence of any systemic illness such as diabetes, hypertension and chronic obstructive airway disease has been noted. History of any surgery in past was asked for and presence of past surgical scar was noted down. A detailed history was taken and clinical examination was done in all the cases. Complete blood count, erythrocyte sedimentation rate (ESR), ultrasonography of abdomen and pelvis, routine urine examination, electrocardiogram (ECG) and chest X-Ray was done in all the cases. Preanesthetic evaluation was done in all the cases. Following this, patients were taken up for surgery. All patients were operated under spinal anesthesia. Other than the different techniques used for fixing the mesh the surgical procedure in both the groups were kept identical. Time required for surgery, postoperative pain, complications and recurrence rates were compared in between these 2 groups. Presence of post-operative pain was assessed by VAS scores and patients were divided into having in mild, moderate or severe pain on the basis of VAS score. Whether Pain affected their daily routine or quality of life was also noted down. Patients were followed up monthly for 6 months. After 3 months if a patient didn't turn up for follow up then a telephonic interview was conducted and presence of pain was assessed. Those patients who were not traceable even on phone were excluded from the study. Microsoft office was used for preparing manuscript, charts and graphs. SSPE 21.0 software was used for statistical analysis and $\mathrm{P}$ value less than 0.05 was taken as statistically significant.

\section{Inclusion Criteria}

1. patients admitted in department of surgery with the diagnosis of inguinal hernia and treated by hernioplasty with mesh fixation.

2. Age above 18 years.

3. Informed consent given by the patient.

4. Those who remained in follow up at least for 6 months following surgery.

5. Exclusion Criteria

6. Patients less than 18 years of age.

7. Patients above 70 years.

8. Patients with unstable hemodynamics.

9. Recurrent hernia or femoral hernia.

10. Emergency conditions such as strangulated or obstructed hernia.

11. Patients in whom surgery was contraindicated.

12. Patients who refused consent or those who were lost to follow up.

\section{RESULTS}

This was a prospective comparative study in which 60 adult patients admitted in department of surgery with the diagnosis of inguinal hernia were enrolled. These 60 patients were divided into 2 groups of 30 patients each depending upon whether mesh fixation was done using polypropylene suture material or tissue adhesive glue was used for mesh fixation.

Out of 60 cases there were 48 (80\%) males and $12(20 \%)$ females with a $\mathrm{M}: \mathrm{F}$ ratio of $1: 0.25$. IN group $A$ there were 25 males and 5 females whereas in group B there were 23 males and 7 females. The gender distribution in both the group was found to be comparable with no statistically significant difference in between the groups.

The analysis of age groups of the affected cases showed that the most common affected age group was found to be 4150 years (46.66\%) followed by 51-60 (30\%) years in group A whereas in group B most common affected age group 
was found to be 51-60 years (53.33\%) followed by 41-50

(26.66\%) years. The mean age in group A and group B was

\begin{tabular}{|l|c|c|c|}
\hline Gender Distribution & Males & Females & P value \\
\hline Group A & 25 & 5 & $\begin{array}{c}\mathrm{P}=0.748 \\
\text { (Not Significant) }\end{array}$ \\
\hline Group B & 23 & 7 & (Nt) \\
\cline { 1 - 3 } Table-1: Gender Distribution of the studied cases. \\
\hline
\end{tabular}

\begin{tabular}{|l|c|c|}
\hline Age Distribution & Group A & Group B \\
\hline 18-30 Yrs & 2 & 1 \\
\hline 31-40 Yrs & 4 & 5 \\
\hline 41-50 Yrs & 14 & 16 \\
\hline 51-60 Yrs & 9 & 8 \\
\hline Above 60 Yrs & 1 & 1 \\
\hline Total & 30 & 30 \\
\hline Mean Age & $41.42+/-9.28$ & $43.78+/-10.20$ \\
\hline $\mathrm{P}=0.35$ (Not Significant) 95\% Cl= -2.6796 to 7.3996 \\
\hline \multicolumn{3}{|c|}{ Table-2: Age Distribution of the cases. } \\
\hline
\end{tabular}

\begin{tabular}{|l|c|c|}
\hline Visual Analogue Scale & Group A & Group B \\
\hline Nil & 0 & 0 \\
\hline Mild (VAS $\leq 3)$ & $22(73.33 \%)$ & $26(86.87 \%)$ \\
\hline Moderate (VAS 4-7) & $8(26.67 \%)$ & $4(13.33 \%)$ \\
\hline Severe (VAS 8-10) & 0 & 0 \\
\hline VAS(Mean \pm SD) & $2.76 \pm 0.92$ & $2.48 \pm 0.76$ \\
\hline P value & 0.2038 (Not Significant) \\
\hline \multicolumn{2}{|c|}{ Table-4: Postoperative VAS scores in studied cases. } \\
\hline
\end{tabular}

found to be $41.42+/-9.28$ and $43.78+/-10.20$ respectively. The mean age of patients in group A and group B was found

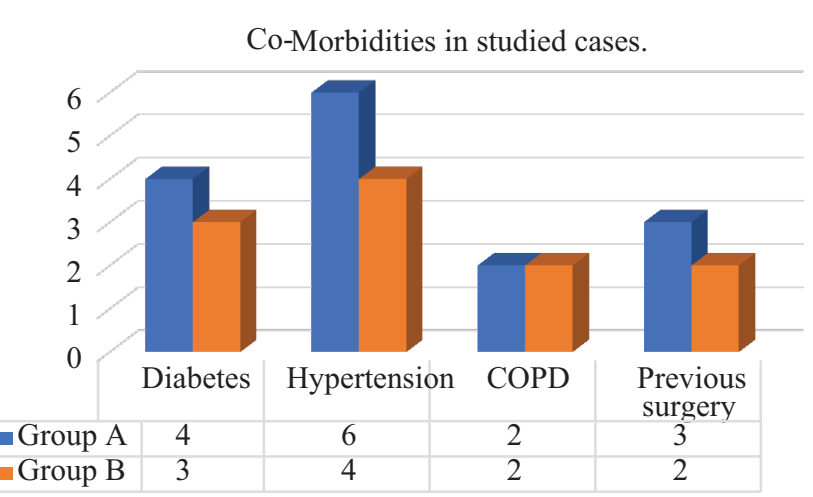

Figure-1: CO-Morbidities in Studied Cases.

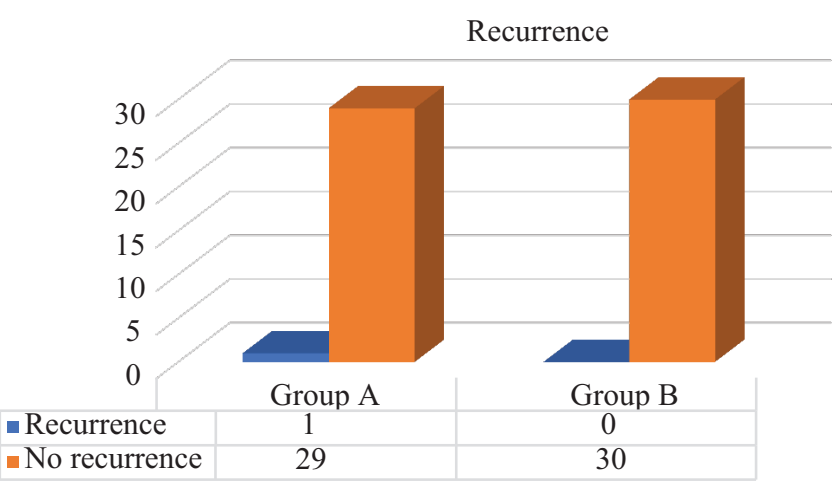

Figure-2: Recurrence Rate in studied cases.

\begin{tabular}{|l|l|c|c|}
\hline & Complications & Group A & Group B \\
\hline \multirow{4}{*}{ Intra-Operative Complication } & Inferior Epigastric Injury & 1 & 0 \\
\cline { 2 - 4 } & Femoral Vein Injury & 0 & 30 \\
\cline { 2 - 4 } & None & 29 & 0 \\
\hline \multirow{3}{*}{$\begin{array}{l}\text { Post-Operative Complications } \\
\text { During Follow up) }\end{array}$} & Hematoma & 1 & 0 \\
\cline { 2 - 4 } & Seroma & 2 & 0 \\
\cline { 2 - 4 } & Tubular Ectasia & 3 & 1 \\
\cline { 2 - 4 } & Scrotal Edema & 2 & 29 \\
\cline { 2 - 4 } & None & 22 & \\
\hline & \multicolumn{2}{|c}{ Table-5: Complications in studied cases. } \\
\hline
\end{tabular}

\begin{tabular}{|c|c|c|c|c|c|}
\hline \multicolumn{2}{|l|}{ Pain } & \multicolumn{2}{|c|}{ Group A } & \multicolumn{2}{|c|}{ Group B } \\
\hline & & \multirow{2}{*}{$\begin{array}{c}\text { No of patients } \\
14 \\
\end{array}$} & \multirow{2}{*}{$\begin{array}{c}\text { Percentage } \\
46.67 \%\end{array}$} & \multirow{2}{*}{$\begin{array}{c}\text { No of patients } \\
20\end{array}$} & \multirow{2}{*}{$\begin{array}{c}\text { Percentage } \\
66.67 \% \\
\end{array}$} \\
\hline At 2 Months Follow Up & Nil & & & & \\
\hline & Mild & 11 & $36.67 \%$ & 7 & $23.33 \%$ \\
\hline & Moderate & 5 & $16.67 \%$ & 1 & $3.33 \%$ \\
\hline & Severe & 0 & $0.00 \%$ & 0 & $0.00 \%$ \\
\hline \multirow[t]{4}{*}{ At 4 Months Follow Up } & Nil & 22 & $73.33 \%$ & 26 & $86.67 \%$ \\
\hline & Mild & 6 & $20.00 \%$ & 3 & $10.00 \%$ \\
\hline & Moderate & 2 & $6.67 \%$ & 1 & $3.33 \%$ \\
\hline & Severe & 0 & $0.00 \%$ & 0 & $0.00 \%$ \\
\hline \multirow[t]{4}{*}{ At 6 Months Follow Up } & $\mathrm{Nil}$ & 24 & $80.00 \%$ & 29 & $96.67 \%$ \\
\hline & Mild & 6 & $20.00 \%$ & 1 & $3.33 \%$ \\
\hline & Moderate & 0 & $0.00 \%$ & 0 & $0.00 \%$ \\
\hline & Severe & 0 & $0.00 \%$ & 0 & $0.00 \%$ \\
\hline
\end{tabular}


to be comparable with no statistically significant difference $(\mathrm{P}>0.05)$.

The analysis of patients on the basis of presence of systemic illnesses such as diabetes, hypertension and COPD showed that in group A 12 patients were having either diabetes, hypertension or COPD whereas in group B 9 patients were found to have either diabetes, hypertension or COPD. History of previous abdominal surgeries other than surgery for hernia was present in 3 and 2 cases in group A and B respectively.

The analysis of mean operating time between the 2 groups showed that the mean duration of surgery in group $\mathrm{A}$ and group B was found to be $52.32+/-14.74$ minutes and 43.92 +/- 10.64 minutes respectively. The statistical analysis showed that operation time was significantly less in tissue adhesive glue group as compared to the patients in whom sutures were used for mesh fixation $(\mathrm{P}<0.05)$.

The analysis of postoperative pain showed that in immediate postoperative period $22(73.33 \%)$ patients in group A had mild pain and $8(26.67 \%)$ patients had moderate pain. In group B mild and moderate pain was present in 26 (86.87\%) and $4(13.33 \%)$ patients respectively. There was no patient with severe postoperative pain in any of the group Postoperative mean VAS scores were found to be comparable in both the groups with no statistically significant difference $(\mathrm{P}>0.05)$.

The analysis of complications in studied cases showed that out of 30 cases in group A, 1 patient had inferior epigastric injury whereas there were no intraoperative complications in group B. During postoperative period and follow up 8 (26.67\%) patients were found to have complications such as hematoma, seroma, tubular ectasia and scrotal edema in group A whereas only 1 patient (3.33\%) was found to have scrotal edema in group $\mathrm{B}$. The difference in complication was found to significantly higher in group $\mathrm{A}(\mathrm{P}=0.02)$.

The analysis of patients on the basis of presence of pain during follow up period showed that patients in group A had comparatively higher incidence of mild and moderate pain during follow up visits. At 6 months follow up 6 patients in group were found to have mild pain whereas only 1 patient in group B had mild pain. There was no patient with moderate or severe pain at the end of 6 months follow up period.

Finally, the analysis of recurrence rates in studied groups showed that there was no patient with recurrence during 6 months follow up period in group B whereas 1 patient was found to have clinical recurrence during follow up period. Recurrence rates were found to be comparable with no statistically significant difference $(P>0.05)$.

\section{DISCUSSION}

In this study 60 adult patients admitted in department of surgery with the diagnosis of inguinal hernia and undergoing surgical repair were divided into 2 groups of 30 patients each depending upon whether mesh fixation was done using polypropylene suture material or synthetic glue was used for mesh fixation. Out of 60 cases there were $48(80 \%)$ males and 12 (20\%) females with a M:F ratio of 1:0.25. All the studies which included patients of inguinal hernia have uniformly reported that inguinal hernia is predominantly seen in male patients. ${ }^{10}$ In fact, almost up to $90 \%$ of the times inguinal hernia is seen in males whereas only $10 \%$ patients of inguinal hernia are reported to be females. This male preponderance in patients of inguinal hernia has been reported by many authors including Burcharth $\mathrm{J}$ et $\mathrm{al}^{11}$ and et al. ${ }^{12}$

The mean age of the patients in group $\mathrm{A}$ was found to be $41.42+/-9.28$ whereas mean age of patients in group $B$ was found to be $41.42+/-9.28$. Anitha $B$ et al conducted a study to analyze the morphometric features of the inguinal canal with different types of inguinal hernias to determine the appropriate size of mesh required to cover potential sites of recurrence. ${ }^{13}$ The study included a total of 170 patients with a mean age of $50.67+17.59$ years. The mean age of our patients was found to be slightly less than mean age reported in this study. Other authors such as Kayaoglu HA et $\mathrm{a}^{14}$ and Sönmez MG et $\mathrm{al}^{15}$ reported the mean age of patients with inguinal hernia to be $45.68 \mathrm{yr}$. and 46.2 years.

The analysis of time required for surgery in both the groups showed that the mean duration of surgery in group A (suture group) and group B (Synthetic glue) was found to be $52.32+/-14.74$ minutes and $43.92+/-10.64$ minutes respectively. Statistical analysis showed that suture group required significantly more time for surgery as compared to glue group. Jeyakumar $\mathrm{S}$ et al conducted a prospective study to compare suture fixation versus tissue glue fixation of the mesh in inguinal hernia repair. The authors found that Operative time, measured in minutes was found to be 41.8 minutes on an average with the use of glue and 52.6 minutes with the use of suture. An average difference of 10.8 minutes was seen between the 2 methods with the procedure taking a comparatively longer time to complete when suture was used. This difference was found to be statistically significant. ${ }^{16}$

The analysis of postoperative pain showed that in immediate postoperative period the intensity of pain as measured by VAS was found to be comparable in both the groups but on 2 months and 4 months follow up visits pain was reported by patients in group A (suture group) as compared to group B (Glue group). At the end of 6 months follow up 6 patients in group A reported mild pain whereas only 1 patient reported mild discomfort. Sun $\mathrm{P}$ et al conducted a review of Twelve trials with a total of 1932 participants. The authors found that overall postoperative chronic pain in the glue group was reduced by $37 \%$ (OR $0.63,95 \%$ CI 0.44 to $0.91 ; 10$ studies, 1418 participants, low-quality evidence) compared with the suture group. ${ }^{17}$ Similar low incidence of chronic pain has been reported by the authors such as Quyn AJ et $\mathrm{al}^{18}$ and Zhang C et al. ${ }^{19}$

Finally, the analysis of recurrence rates showed that during follow up period only 1 patient in group A reported recurrence whereas there was no case of recurrence in group B. Many authors have including Colvin HS have reported that the recurrence rates after using synthetic glue were comparable to sutures thereby making synthetic glue a better choice for fixation of mesh as compared to sutures. ${ }^{20}$

\section{CONCLUSION}

Fixation of mesh in inguinal hernial repair by tissue adhesive glue as compared to sutures is associated with decreased operation time, better long-term results in terms of chronic 
post-operative pain and is associated with comparable recurrence rates making tissue adhesive glue a superior choice as compared to sutures for fixation of mesh in inguinal hernia repair.

\section{REFERENCES}

1. Kingsnorth A, LeBlanc K. hernia's: inguinal and incisional . Lancet 2003;362(2):1561-71

2. Amid PK, Lichtenstein tension free hernioplasty:its inception, evolution and princples. Hernia 2004;8(4):17

3. Burger JW, Luijenbijk RW, Hop WC, Halm JA, Berdaasdonk EG, Jeekel J. long-term follow-up of a randomized control trial of suture versus mesh repair of incisional hernia. Ann surg.2004;240(6):578-83

4. Conze J, Kingsnorth AN, Flament JB, Simmermacher $\mathrm{R}$, Arlt $\mathrm{G}$, Langer $\mathrm{C}$, et al. randomised clinical trail comparing lightweight composite mesh with polyester or polypropylene mesh for incisional hernia repair. $\mathrm{Br} \mathrm{J}$ Surg.2005;92(1):1488-93

5. Martin-Duce A, Noguerales F, Villeta R, Hernandez P, Lozano O, Keller J, et al. Modification to Rives technique for midline incisional hernia repair. Hernia. 2001;5(3):70-2

6. Fortelny RH, Petter-Puchner AH, Glaser KS, Redl H. Use of fibrin sealant (Tisseel/Tissucol) in hernia repair: A systematic review. Surg Endosc 2012;26(5):1803-12

7. Helbling C, Schlumpf R. Sutureless Lichtenstein: first results of prospective randomised clinical trial. Hernia 2003;7(2):80-4

8. Brown C.N., Finch J.G. which mesh for hernia repair? Ann R Coll Surg Engl 2010;92(4):272-278

9. Matthews RD, Neumayer L. inguinal hernia in the $21^{\text {st }}$ century; and evidenced based review. Curr probl surg 2008:45:261-312

10. Jenkins JT, O'Dwyer PJ. Inguinal hernias. BMJ. 2008;336(7638):269-272.

11. Burcharth J, Pedersen M, Bisgaard T, Pedersen C, Rosenberg J. Nationwide prevalence of groin hernia repair. PLoS One. 8(1):e54367.

12. Olasehinde OO, Adisa AO, Agbakwuru EA, Etonyeaku AC, Kolawole OA, Mosanya AO. A 5-year Review of Darning Technique of Inguinal Hernia Repair. Niger J Surg. 2015;21(1):52-55.

13. Anitha B, Aravindhan K, Sureshkumar S, Ali MS, Vijayakumar C, Palanivel C. The Ideal Size of Mesh for Open Inguinal Hernia Repair: A Morphometric Study in Patients with Inguinal Hernia. Cureus. 2018;10(5):e2573.

14. Kayaoglu HA, Hazinedaroglu SM, Bulent Erkek A, Kocaturk PA, Kavas GO, Aribal D. Comparison of the plasma and hernia sac tissue copper levels in direct and indirect inguinal hernia patients. Biol Trace Elem Res. 2005 Winter;108(1-3):53-9.

15. Sönmez MG, Sonbahar BÇ, Bora G, Özalp N, Kara C. Does inguinal hernia repair have an effect on sexual functions?. Cent European J Urol. 2016;69(2):212-216.

16. Jeyakumar S, Chitrambalam TG, Chandrasekaran S. Glue versus suture for mesh fixation in open inguinal hernia repair. Int Surg J 2018;5(3):1443-8.

17. Sun P, Cheng X, Deng S, Hu Q, Sun Y, Zheng Q.
Mesh fixation with glue versus suture for chronic pain and recurrence in Lichtenstein inguinal hernioplasty. Cochrane Database Syst Rev. 2017 Feb 7;2:CD010814.

18. Quyn AJ, Weatherhead KM, Daniel T. Chronic pain after open inguinal hernia surgery: suture fixation versus self-adhesive mesh repair. Langenbecks Arch Surg. 2012;397(8):1215-8.

19. Zhang C, Li F, Zhang H, Zhong W, Shi D, Zhao Y. Self-gripping versus sutured mesh for inguinal hernia repair: a systematic review and meta-analysis of current literature. J Surg Res. 2013;185(2):653-60.

20. Colvin HS, Rao A, Cavali M, Campanelli G, Amin AI. Glue versus suture fixation of mesh during open repair of inguinal hernias: a systematic review and metaanalysis. World J Surg. 2013;37(10):2282-92.

\section{Source of Support: Nil; Conflict of Interest: None}

Submitted: 16-05-2019; Accepted: 12-06-2019; Published online: 15-07-2019 